\title{
Turning the Heat on Cancer
}

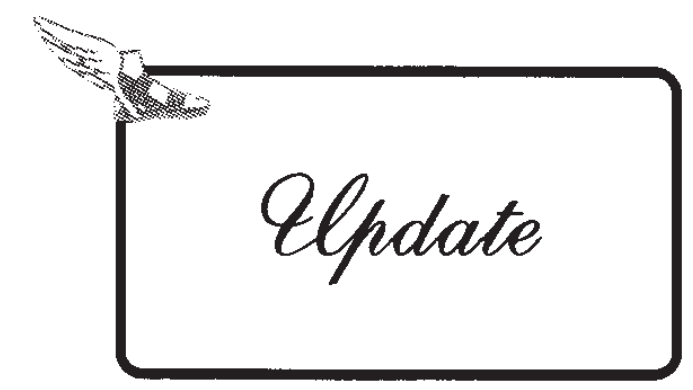

\author{
Gerald L. DeNardo and Sally J. DeNardo \\ Cancer Center, University of California Davis Medical Center, Sacramento, CA
}

\section{SUMMATION}

The promise of hyperthermia has yet to be realized, but the fundamental idea and the effects of heat on (cancer) cells are well known. Cell death from exposure to heat is a function of both the intensity of the heat and the length of the exposure. Cells die by necrosis and by apoptosis. Sublethal heat doses sensitize cancer cells to radiation and drugs. Because of advances in chemistry and physics, harnessing the power of heat to kill cancer cells seems achievable now! Using novel systems embodied in the combination of molecular-targeted nanoparticles and hysteretic heating of the nanoparticles with "focused" alternating magnetic frequencies (AMFs), heat delivery can be better controlled. Importantly, hyperthermia does not damage, and may actually enhance, the immune system. Trials in patients are needed to settle the clinical role of new thermal treatment.

Key words: breast cancer, antibody, biotherapy, immunotherapy, imaging

"Those who cannot be cured by medicine can be cured by surgery. Those who cannot be cured by surgery can be cured by fire [hyperthermia]. Those who cannot be cured by fire, they are indeed incurable."

-Hippocrates (479-377 B.C.)

\section{TREATING CANCER WITH HEAT: PAST AND PRESENT}

The use of elevated temperature, hyperthermia, is not a new treatment for cancer. Hippocrates was aware of the potential of heat to cure or shrink tumors. Tumor shrinkage after a high fever due to an infection was reported in $1866 .{ }^{1}$ Heat has profound effects on cells. At low doses, heat enhances recovery from injury. At high doses, it

Address reprint requests to: Gerald L. DeNardo, Cancer Center, University of California Davis Medical Center, 1508 Alhambra Boulevard, Room 3100, Sacramento, CA 95816; Tel.: 916-734-3787; Fax: 916-703-5014

E-mail: gldenardo@ucdavis.edu leads to cell death that may be immediate for extreme doses. Because of these effects, heat treatment or thermal therapy is potentially potent against cancer. The effects of heat on cancer cells are well-known. ${ }^{2}$ Cell death from exposure to heat is a function of both the intensity of the applied heat and the time of exposure. Cells die at high dose-time combinations by necrosis. ${ }^{3}$ For milder exposure conditions, cells undergo apoptosis. Sublethal heat insufficient to cause cell death sensitizes cancer cells to radiation and many drugs. ${ }^{4}$ Clinical trials have shown that the outcome measured by patient survival and tumor regression is often much better when heat and radiation are combined. ${ }^{5}$ The combined effect of heat and radiation is referred to as heat or thermal radiosensitization. Hyperthermia may be the most potent radiosensitizer known to date. A similar effect is observed with many chemotherapeutic drugs. ${ }^{6}$ Heat damages proteins required to repair DNA damage. Normal cells typically recover faster than cancer cells when exposed to either heat or the combination of heat and radiation. Additionally, normal tissues have more 
blood flow than cancerous tissue so that they dissipate heat better. If the heat is interrupted, then thermal recovery occurs; normal tissues such as the skin are particularly effective in dissipating heat. For cancer treatment, this is fortunate.

Despite its effectiveness, the promise of hyperthermia as a stand-alone treatment for cancer has yet to be realized, with few exceptions. Major technical barriers have been an inability to localize effective levels of heat in the cancer without subjecting the patient to dangerous stress. ${ }^{7,8}$ Thus, techniques for more selective heat delivery and noninvasive, predictive tissue dosimetry are needed to exploit the potential of hyperthermia to treat cancer.

Heating has been accomplished by using various methods, including: (1) thermal conduction of heat away from a source at higher temperature; (2) a combination of resistive and dielectric losses in tissue from an applied electromagnetic field; (3) insertion of a susceptor material in tissues that heats from an applied electromagnetic field; or (4) mechanical losses from molecular oscillations caused by an ultrasonic pressure wave. In the simplest forms of hyperthermia, tissue is heated by circulating externally preheated blood through the tissue, by placing a heated surface on the skin or body cavities, or by implanting wire, needle, or catheter heat sources. Other heating methods include shortwave diathermy, radiofrequency capacitative heating, microwaves, ultrasound, and interstitial implants. ${ }^{6}$

Thermal treatment for cancer has typically been limited to superficial cancers. ${ }^{9}$ In the clinical application of hyperthermia, three methods can be distinguished: local, regional, and wholebody hyperthermia. The disadvantages of wholebody heating are the systemic stress that results from a lack of preferential heating. ${ }^{10}$ Despite this serious limitation, some success was achieved with whole-body hyperthermia, particularly when used in combination with drugs and radiation.

Local and regional application of hyperthermia has the potential to avoid some of the limitations of whole-body hyperthermia. These methods require that heat be focused on the cancer, using heat-delivery systems that better control the location and dose of applied heat. Electromagnetic fields have been used to localize and concentrate heat by either directly heating the tissue or activating a susceptor material. Examples include the surgical insertion of radiofrequency probes, or "thermal seeds" for the treatment of liver and prostate cancers, respectively. Disadvantages of these approaches include their invasive nature and the relatively indiscriminate nature of the tissue damage. These drawbacks are overcome, to some extent, by the development of microwave antenna arrays to apply the heat remotely. Radiofrequency and microwave treatment suffer from energy deposition in intervening tissues when the energy source is also the heat source or the heat from the susceptor substance damages normal tissue.

In 1957, Gilchrist et al. ${ }^{11}$ treated metastatic cancer in lymph nodes by using 20-100 nanometer magnetic iron oxide $\left(\mathrm{Fe}_{2} \mathrm{O}_{3}\right)$ particles injected into lymphatic channels draining into the lymph nodes. The particles were induced to heat by exposure to an alternating radiofrequency magnetic field (AMF). This work showed that the combination of magnetic particles and AMF were a suitable combination of materials and energy to produce intratumoral heating. The tissue heating came from hysteresis losses or "magnetic friction" from the magnetic particles, rather than the inductive tissue heating that results from dielectric or eddy current losses. Subsequent work by others further explored this approach to hyperthermia for cancer by using magnetic particles directly injected into tumors. ${ }^{12}$

\section{NANOTECHNOLOGY FOR THE FUTURE}

Advances in chemistry and physics have provided an attractive array of nanoparticles and devices for use in biomedical applications. ${ }^{13}$ For drug delivery, liposomes or other polymer-based nanoparticles can be used to transport drug payloads to be released by induced heating that "melts" the polymer shell. Iron nanoparticles in the cancer can be heated by an external magnetic field set to frequencies that produce heat within the cancer. For the magnetic resonance imaging (MRI) of cancer, superparamagnetic 5-10-nm iron-oxide particles are in clinical trials.

Several years ago, scientists at a military technology company developed resin-impregnated magnetic nanoparticles designed to heat when exposed to a magnetic field to repair military armor and to warn of the presence of biologic and chemical warfare agents. These scientists hypothesized that a biocompatible magnetic nanoparticle attached to an antibody could target cancer cells, precluding the need to inject the particles directly into the cancer. Collaborative studies with scien- 
tists from the University of Massachusetts suggested the selectivity of antibody-conjugated iron-oxide nanoparticles to kill cancer cells in culture.

\section{NOVEL MOLECULAR APPROACH TO THERMAL THERAPY}

The ability to combine targeting antibodies with a nanoparticle, inactive until exposed to AMF, afforded an opportunity for heat to be delivered selectively to the cancer, if the AMF energies were confined to the region to be treated. These molecular techniques to deliver heat to cancer cells have created a renaissance for thermal treatment.

In one system (TNT ${ }^{\mathrm{TM}}$; Triton BioSystems, Inc., Chelmsford, MA) in development to treat cancer, trillions of AMF-responsive nanoparticles conjugated to anticancer monoclonal antibodies (bioprobes), when infused into the bloodstream, seek and bind to (target) receptors on the cancer cells, so that an external AMF device can be used to induce heating of the cancer cell-bound bioprobes (Fig. 1). The AMF device is aligned to direct the energy to the area where the nanoparticles convert the magnetic energy to thermal energy, leading to cell death. The technique exploits the combination of magnetic

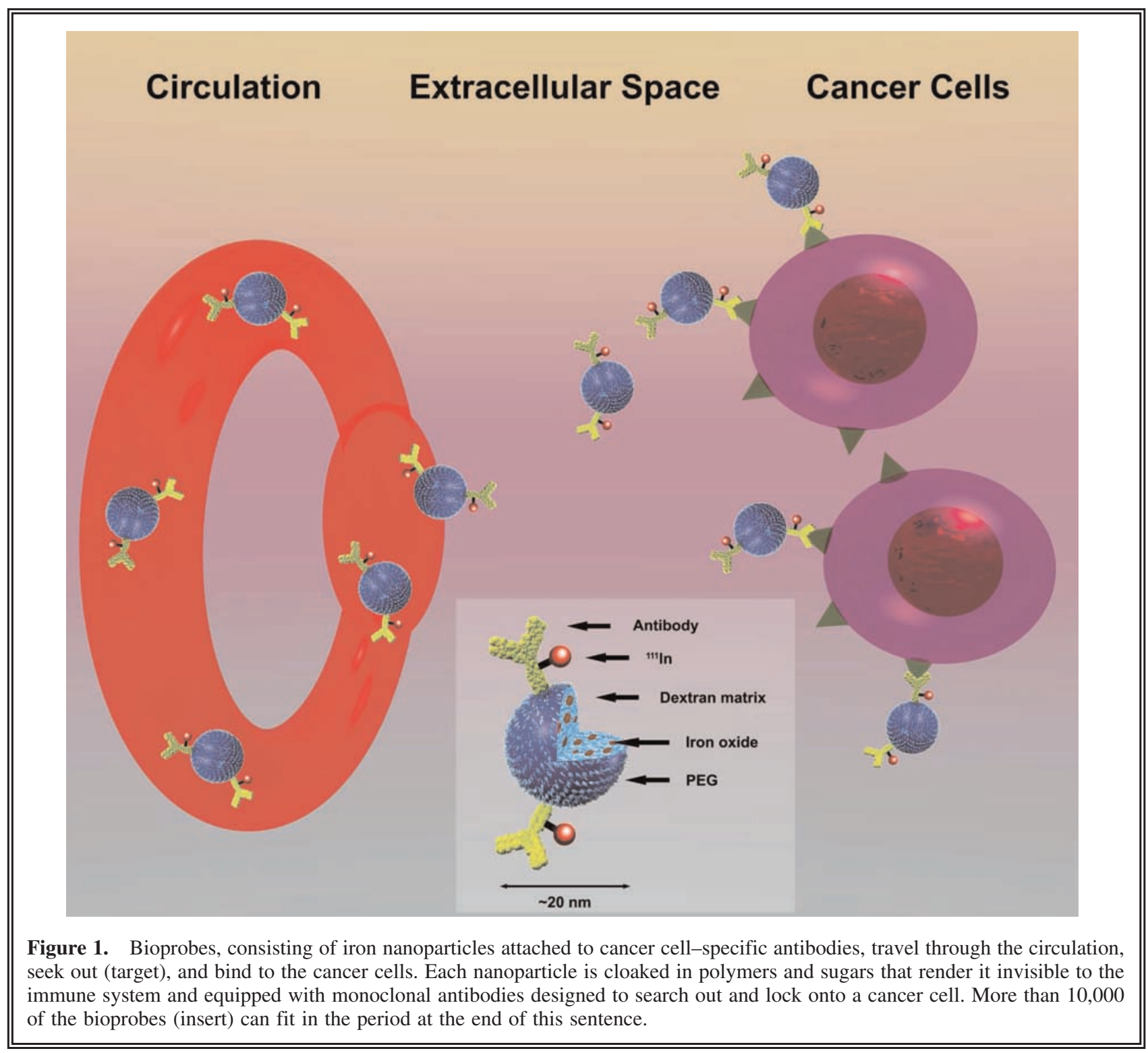


nanoparticles localized in the cancer and an AMF coil that can be switched on and off to selectively heat the targeted nanoparticles, thereby inducing heat focused in the cancer to destroy the cells. By virtue of their antibody specificity, the bioprobes bind to antigen expressed on the cancer cells, and the heat is focused on the cancer cells because of the nanoparticles (Fig. 2). Selectivity is achieved because two conditions must exist to create cellkilling levels of heat: (1) a concentration of nanoparticles sufficient to generate heat and (2) an alternating magnetic field with sufficient "power" to induce the nanoparticles to heat. Proof of concept has been shown for a model bioprobe (Fig. 1) and AMF device (Fig. 3) in a mouse model bearing an aggressive human breast cancer xenograft. The treatment consisted of: (1)

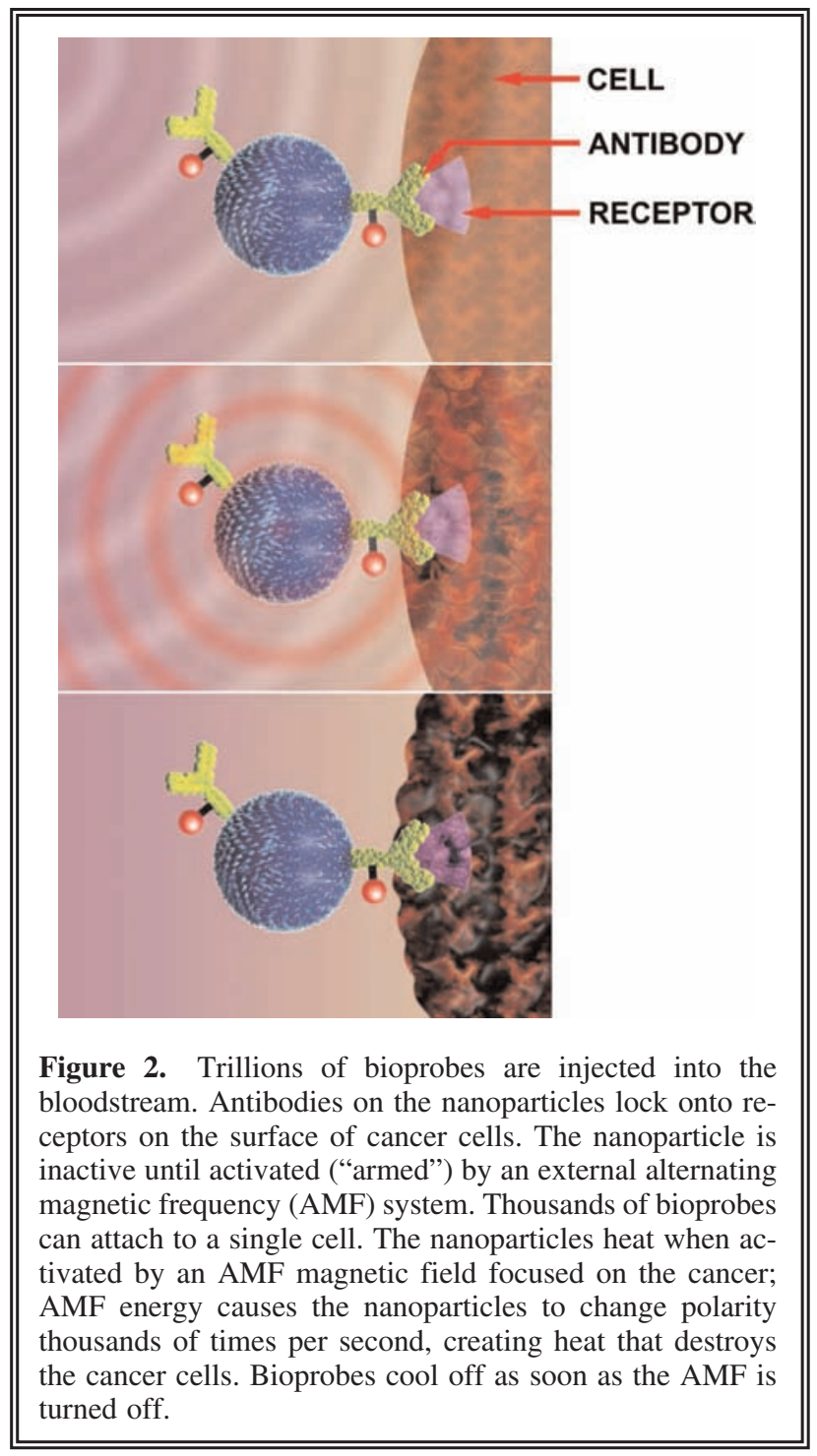

magnetic nanoparticles, bound to antibodies (bioprobes) that targeted the cancer cells when introduced intravenously, and, (2) an external AMF that selectively heated the bioprobes to kill the cancer cells. The system, embodied by the combination of both antibody-directed bioprobes and focused AMF, used magnetic energy to heat up nanoparticles locked onto cancer cells, killing at the cellular level with very high temperatures (Fig. 4). The bioprobes had a diameter of $20 \mathrm{~nm}$ and consisted of a magnetite $\left(\mathrm{Fe}_{3} \mathrm{O}_{4}\right)$ core coated with dextran and a biocompatible polymer (polyethylene glycol) coating to which an antibody, specific for a cancer antigen, was covalently bound (Fig. 1). These studies documented that the bioprobes lock onto human breast cancer cells grafted into mice, and that sufficient heat was generated to induce these human cancers to regress. ${ }^{14}$ After only 20 minutes of treatment, significant tumor regression and cell death by necrosis were observed (Fig. 5), suggesting very intense local heat (i.e., thermal ablation). Hyperthermia, at temperatures typically below $42^{\circ} \mathrm{C}$, requires 1-6 hours of treatment to show an observable effect. The magnetic field alone and the bioprobes alone induced no effect, because bioprobes that are not exposed to the AMF do not heat, and conversely, AMF interacting with tissue in the absence of bioprobes does not generate substantial heat under these conditions.

AMF strategies to enhance the tumor effect and to permit normal tissues to recover were employed: (1) AMF technology restricted the tissue exposed to that of the tumor and, (2) discontinuous AMF allowed normal tissues to dissipate the heat produced by eddy currents. ${ }^{15}$ To confine most of the AMF energy to the tumor tissue, the primary energy from the AMF coil was "focused" on a restricted region. When calculated, using tumor-bioprobe concentrations from biodistribution studies and AMF "power" parameters, macroscopic estimates of the tumor heat correlated with tumor response, with the best tumor response corresponding to the highest deposited heat of about $20 \mathrm{~J}$ per $\mathrm{g}$ of tumor. ${ }^{16}$ This amount of heat seems low for the observed tumor responses, and suggests that microscopic doses at the cell-surface membrane location of the bioprobes were much higher. Electron micrographs showed that the tumors exhibited widespread necrotic cell death. This damage may be the consequence of bioprobe proximity to the cell because they are bound to the cell membrane by the antibody-antigen complex, as shown in the elec- 

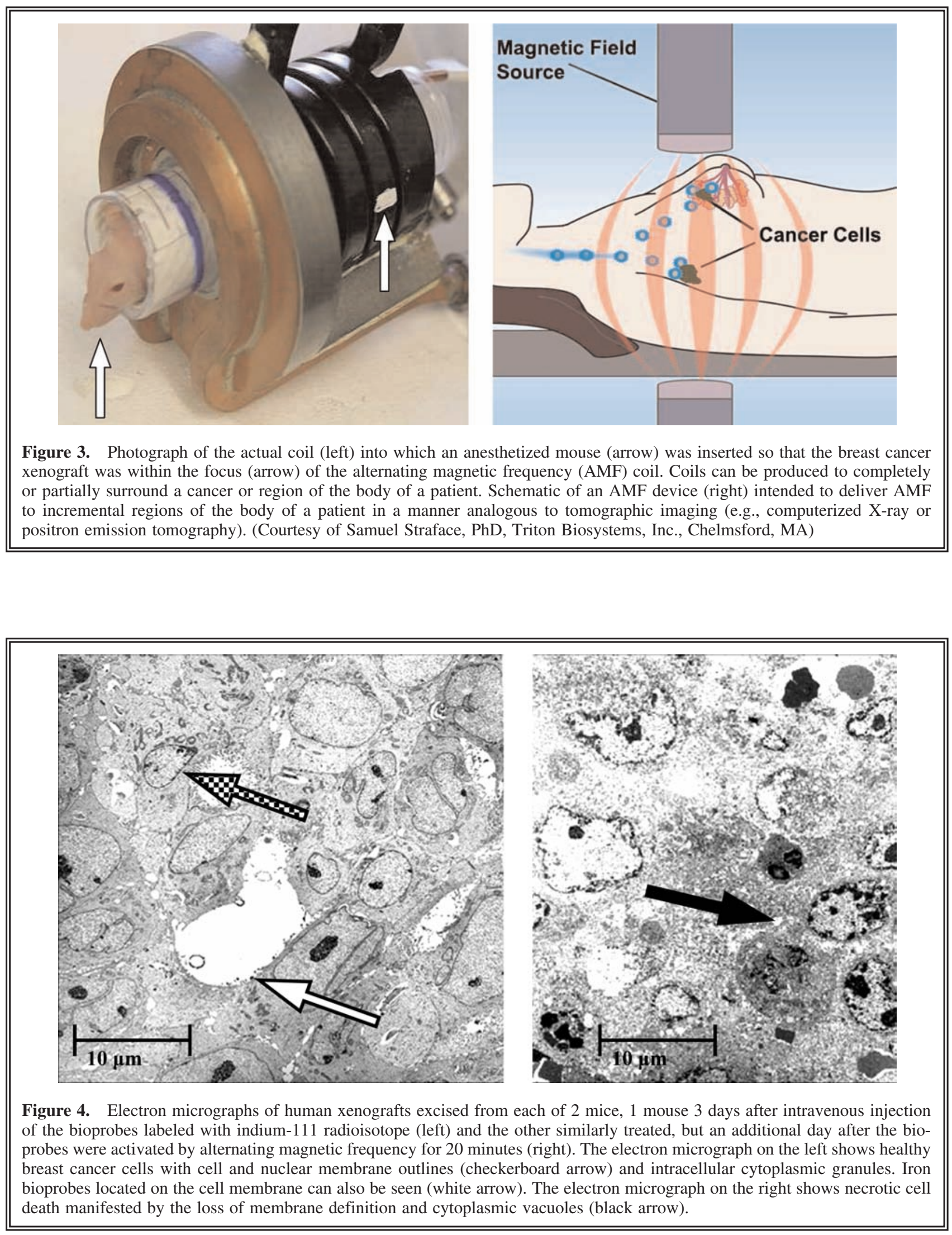


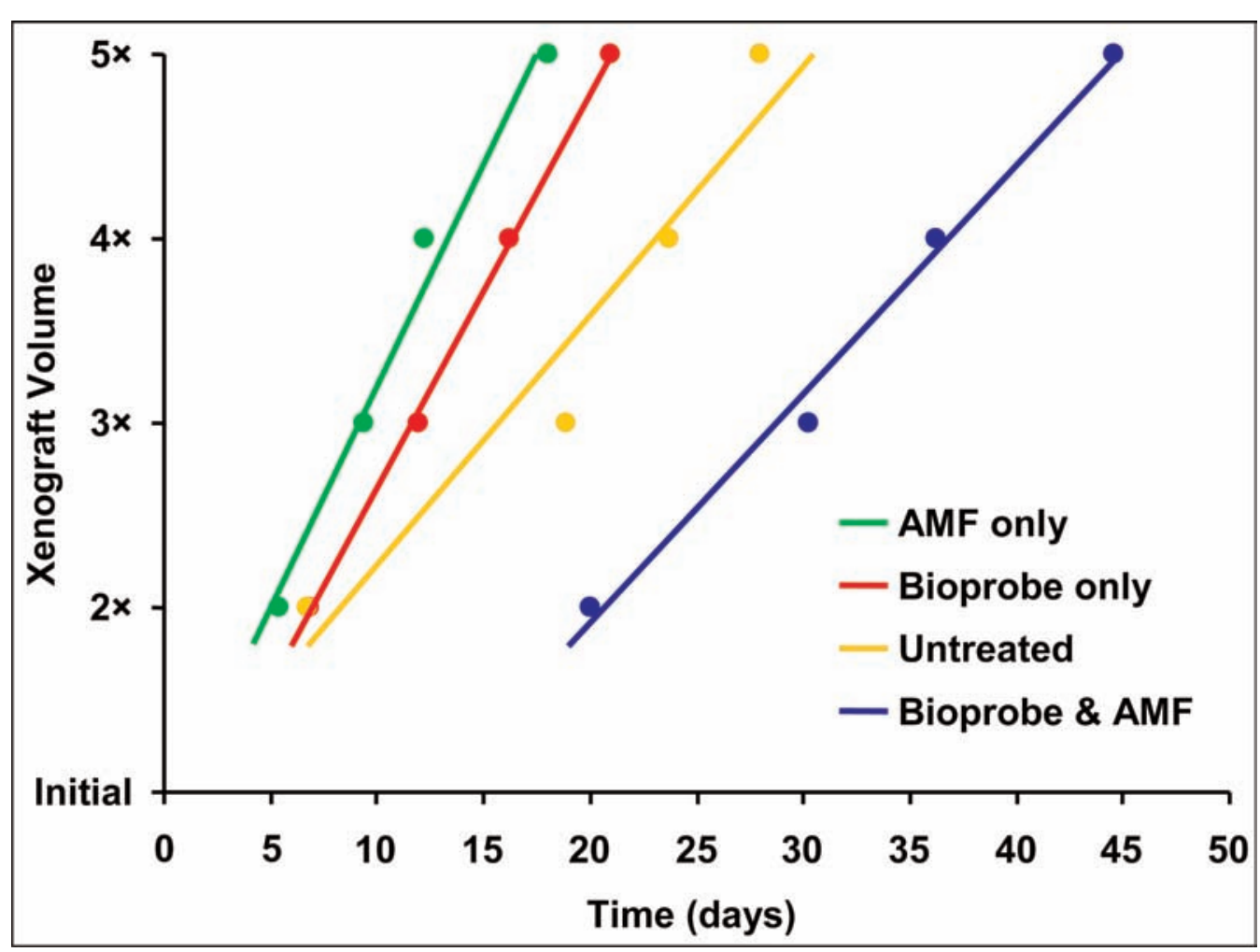

Figure 5. Growth delay for human breast cancer xenografts in mice. The time to double, triple, and so forth, the xenograft volumes was significantly delayed when the mice were given bioprobes that were then activated by alternating magnetic frequency (AMF) (blue), as compared to the untreated mice (yellow) or mice treated only with bioprobes (red) or AMF (green). The xenografts treated with bioprobes and AMF required about 20 days to double in volume, whereas the xenografts in other groups doubled in about 5-6 days.

tron micrographs. ${ }^{12,16}$ Consequently, the cell membrane absorbs much of the heat before the heat dissipates into a larger space.

\section{THERMAL CONTROL OPPORTUNITIES}

An advantage of this system is the level of control. Heat is delivered only when the AMF device is on, and occurs primarily in tissues that receive a sufficient combination of bioprobes and AMF energy. The iron-oxide bioprobes are inert and expected to clear through normal iron pathways. Pulsing the AMF reduces normal tissue heating by allowing these tissues to dissipate nonspecific heat deposited due to eddy currents (Fig. 6). Nanoparticles with a much higher heat production, that is, 5-10 times greater, have been produced. Other opportunities to improve effectiveness and safety include the ability to: (1) fractionate the AMF dose; (2) vary the AMF treatment time; (3) vary the AMF pulse sequence; (4) fractionate the bioprobe dose; (5) administer multiple bioprobe injections; and (6) repeat AMF treatments over time after a single bioprobe dose.

\section{THERMAL TREATMENT OF PATIENTS}

The "power" required to treat patients seems likely to be much greater than that required to treat mice and represents a barrier to the scaleup from mice to human patients. As suggested earlier, there are also innumerable opportunities for improvements, however. The development of a noninvasive, albeit macroscopic, thermometry system was an important one made possible because of the radioactive isotope (and the iron oxide) incorporated in the bioprobes. ${ }^{16}$ Because the bioprobes are "labeled," the amount of bioprobes in the tissues can be accurately quantitated. In- 


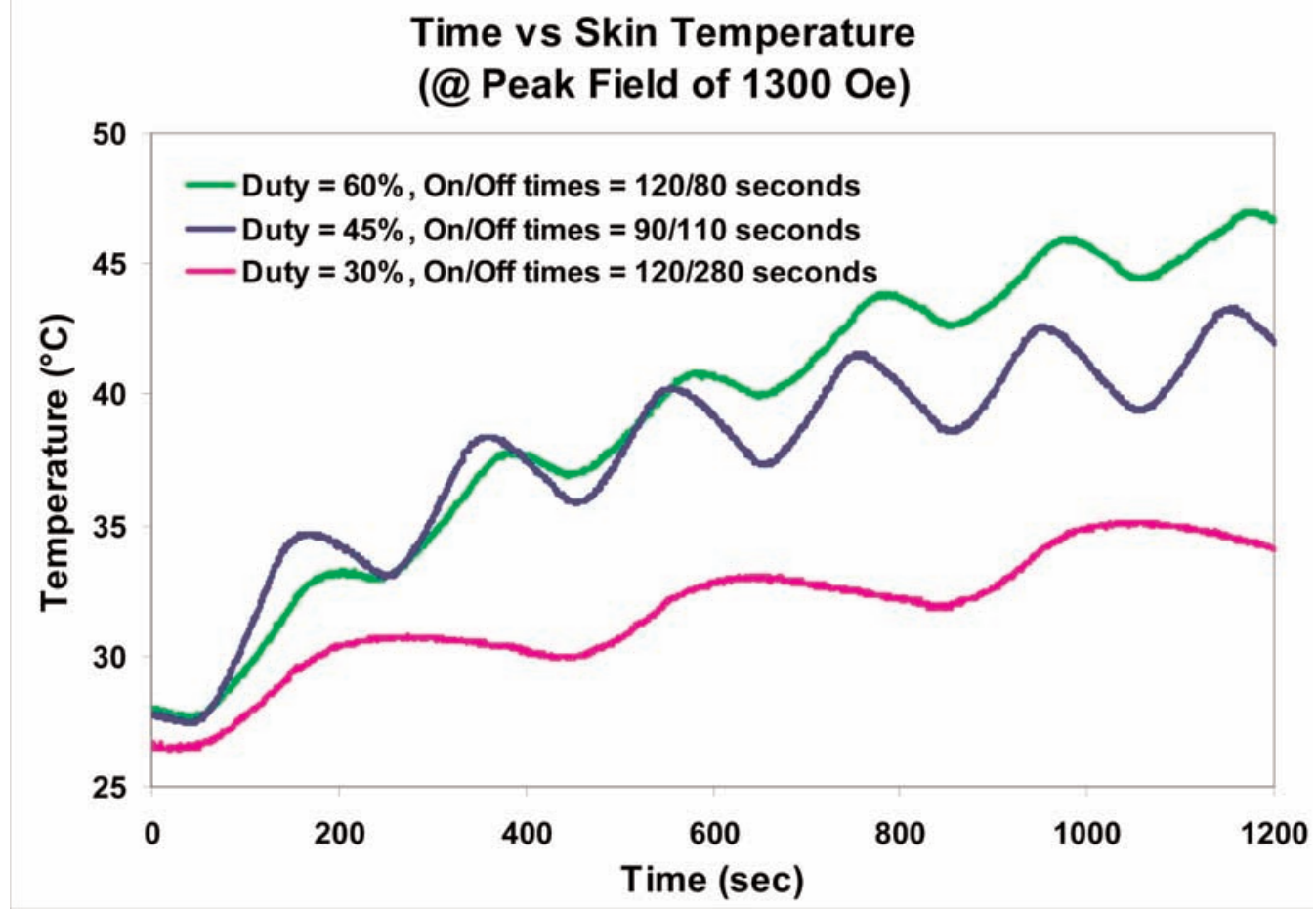

Figure 6. Evidence for thermal recovery of a normal tissue in mice. The skin temperature, heated by eddy currents, at a constant alternating magnetic frequency (AMF) of 1300 Oersteds (Gauss) was also influenced by the duty, the ON/OFF fractions of time, and the total "exposure" time over which the AMF was delivered. A lower duty (greater OFF time) permitted the temperature to return toward the normal baseline temperature, because homeostatic mechanisms facilitated heat dissipation. Duty conditions were 60\% (On/Off: 120/80 seconds), 45\% (On/Off: 90/110 seconds), and 30\% (On/Off: 120/280 seconds), respectively.

dium-111 ( $\left.{ }^{111} \mathrm{In}\right)$, a radioactive isotope routinely used for patient imaging, provides information on bioprobe localization and pharmacokinetics that is available before AMF is applied for treatment (Fig. 7). Similarly, the iron oxide in the nanoparticles can be detected by using MRI. These data represent information required for calculation of macroscopic tissue heat. Obviously, quantitative nuclear imaging or MRI can be used in future applications in patients to derive this information.

\section{CONCLUSIONS}

Hyperthermia is a promising approach. Hysteretic heating of magnetic nanoparticles with AMF can be used to treat cancer with little damage to normal tissues. This technique avoids the marrow suppression that results from many drugs or high levels of radiation. The idea of harnessing the power of heat to kill cancer cells seems

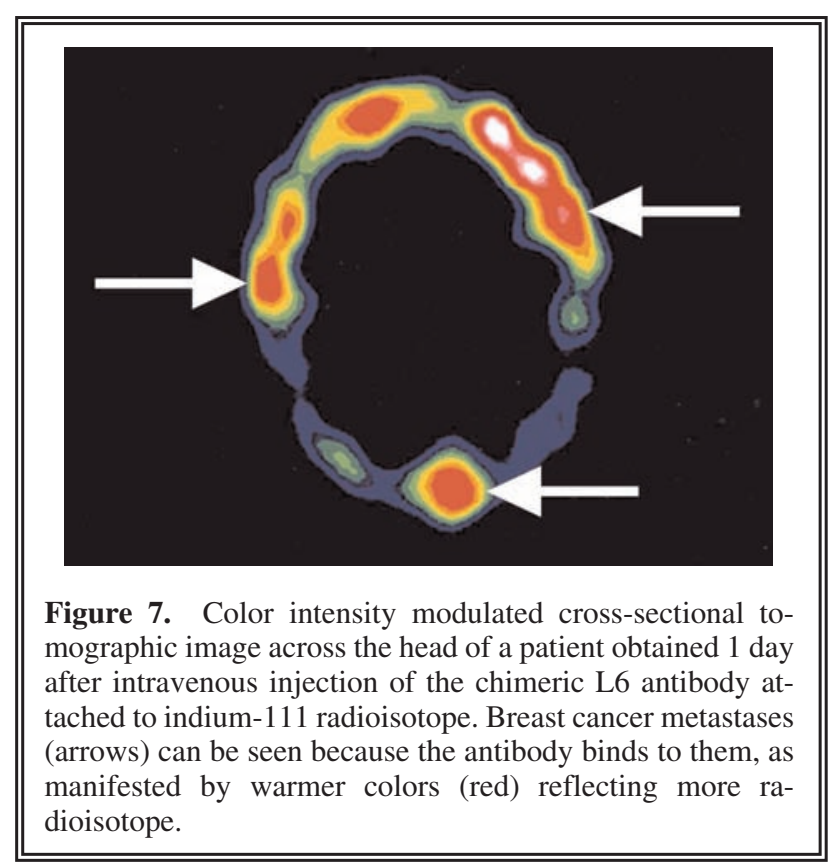


achievable now! Using novel systems, heat delivery can be better controlled. Significant advantages offered by the system described in this paper are its selectivity, noninvasive mode of action, and attractive adverse event profile. The cancer-selective nature of the system is embodied in the combination of the antibody-targeted bioprobes and the focused AMF. Another advantage of the system is the level of control. Heat is delivered only when the AMF device is on and occurs only in tissues that possess the combination of bioprobes in sufficient concentration and energized by an AMF field. Finally, hyperthermia does not damage, and may actually enhance, the immune system, when compared to other cancer therapies. ${ }^{13,19}$ Trials in patients are needed to settle the clinical role of new thermal treatment and to address preferable strategies.

\section{ACKNOWLEDGMENTS}

This work was primarily supported by grants from the Department of Defense, National Cancer Institute, and Department of Energy. The authors are grateful to many individuals for their contributions, including Samuel Straface, $\mathrm{PhD}$, Allen Foreman, $\mathrm{PhD}$, Robert Ivkov, $\mathrm{PhD}$, and Arutselvan Natarajan, PhD.

\section{DISCLOSURE STATEMENT}

No competing financial interests exist.

\section{REFERENCES}

1. Busch W. Uber den Einfluss, welchen heftigere Erysipelin zuweilig auf organisierte Neubildungen ausuben. Verhandlugen des naturhistorischen Vereines der preussischen Rheinlande und Westphalens 1866; 23:28.

2. Dewhirst MW, Viglianti BL, Lora-Michiels M, et al. Basic principles of thermal dosimetry and thermal thresholds for tissue damage from hyperthermia. Int $J$ Hypertherm 2003;19:267.

3. Vorotnikova E, Ivkov R, Foreman A, et al. The magnitude and time-dependence of the apoptotic response of normal and malignant cells subjected to ionizing radiation versus hyperthermia. Int J Radiat Biol 2006; 82:549.
4. Rand RW, Snow HD, Elliott DG, et al. Thermomagnetic surgery for cancer. Appl Biochem Biotechnol 1981;6:265.

5. van der Zee J, Gonzalez D, van Rhoon GC, et al. Comparison of radiotherapy alone with radiotherapy plus hyperthermia in locally advanced pelvic tumors: A prospective, randomized, multicentre trial. Lancet 2000;355:1119.

6. Hildebrandt B, Wust P, Ahlers O, et al. The cellular and molecular basis for hyperthermia. Crit Rev Oncol/ Hematol 2002;43:33.

7. Gerard H, van Echo DA, Whitacre M, et al. Doxorubicin, cyclophosphamide, and whole-body hyperthermia for treatment of advanced soft-tissue sarcoma. Cancer 1984; 53:2585.

8. Moroz P, Jones SK, Gray BN. Magnetically mediated hyperthermia: Current status and future directions. Int J Hypertherm 2002;18:267.

9. Hall EJ, Garcia AJ. Radiobiology for the Radiologist, 6th ed. Philadelphia: Lippincott Williams \& Wilkins, 2005.

10. Dewhirst MW, Jones E, Samulski T, et al. Hyperthermia. In: Kufe D, Pollack R, Weichsolbaum R, et al., eds. Cancer Medicine. Hamilton Ontario, Canada: BC Decker, 2003:623.

11. Pettigrew RT, Galt JM, Ludgate CM, et al. Clinical effects of whole-body hyperthermia in advanced malignancy. Br Med J 1974;4:679.

12. Gilchrist RK, Medal R, Shorey SD, et al. Selective inductive heating of lymph nodes. Ann Surg 1957;146: 596.

13. Jordan A, Scholz R, Wust P, et al. Magnetic fluid hyperthermia (MFH): Cancer treatment with AC magnetic field induced excitation of biocompatible superparamagnetic nanoparticles. J Magnetism Magnetic Mater 1999;201:413.

14. Ito A, Honda H, Kobayashi T. Cancer immunotherapy based on intracellular hyperthermia using magnetite nanoparticles: A novel concept of "heat-controlled necrosis" with heat shock protein expression. Cancer Immunol Immunother 2006;55:320.

15. DeNardo SJ, DeNardo GL, Miers LA, et al. Development of tumor targeting bioprobes ((111)In-chimeric L6 monoclonal antibody nanoparticles) for alternating magnetic field cancer therapy. Clin Cancer Res 2005; 11:7087s.

16. Ivkov R, DeNardo SJ, Daum W, et al. Application of high amplitude alternating magnetic fields for heat induction of nanoparticles localized in cancer. Clin Cancer Res 2005;11:7093s.

17. DeNardo SJ, DeNardo GL, Natarajan A, et al. Thermal dosimetry predictive of efficacy of ${ }^{111} \mathrm{In}$-ChL6 nanoparticle AMF-induced thermoablative therapy for human breast cancer in mice. J Nucl Med 2007;48:437.

18. Olkowski ZL, and Jedrzejczak WW. Responses of immune system to hyperthermia. Adv Exp Med Biol 1990;267:507. 
About the authors

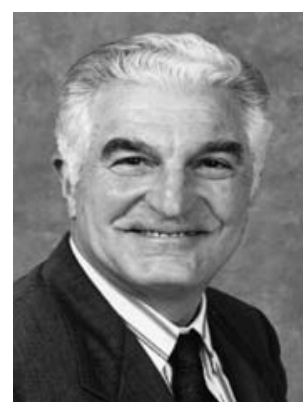

Gerald L. DeNardo received his medical degree from the University of California School of Medicine in San Francisco in 1957. Following internship and training in Internal Medicine and Nuclear Medicine and military service, he began his academic career at the University of Colorado in 1961 and at Stanford in 1965. He joined the Departments of Radiology and Medicine at the University of California, Davis School of Medicine in 1970. Dr. DeNardo specializes in systemic radiotherapy for the treatment of lymphoma, leukemia, and metastatic breast and prostate cancers, currently focusing on novel, small molecules. He has been the recipient of the Cassen Prize for 2000, presented at the 47th Annual Meeting of the Society of Nuclear Medicine, St. Louis, Missouri, and the Berson-Yallow Award in 1978 and 1984. Dr. DeNardo is currently Professor Emeritus in Internal Medicine, Radiology and Pathology at the University of California, Davis School of Medicine and a member of its Cancer Center.
Sally J. DeNardo received her medical degree from the University of Chicago, Pritzer School of Medicine in 1965, and postdoctoral training in Internal Medicine, Hematology/Oncology and Nuclear Medicine at Stanford from 1965 to 1971. She then joined

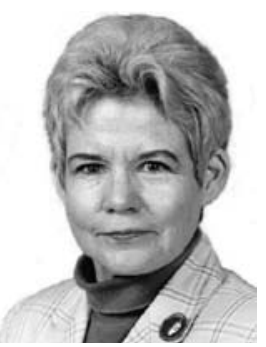
the faculty of the University of California, Davis School of Medicine. Her primary clinical and research focus has been nuclear oncology: development and evaluation of new tumor-targeting antibody or recombinant fragment radiopharmaceuticals for cancer therapy and imaging. She serves on the American Board of Nuclear Medicine and on the Editorial Boards of several journals. Dr. DeNardo is a senior Professor of Internal Medicine (Hematology/Oncology) and Radiology (Nuclear Medicine) at the University of California, Davis School of Medicine and a member of its Cancer Center. 
